Ana Carolina Galvão Marsiglia Universidade Federal do espírito Santo, UFES

E-mail: galvao.marsiglia@gmail.com

(D) http://orcid.org/0000-0001-8451-8269

Maria Cláudia da Silva Saccomani

Universidade Estadual Paulista, UNESP

E-mail:mariaclaudiasaccomani@hotmail.com (D) http://orcid.org/0000-0003-0397-2262

Recebido em: 03/06/2017 Aprovado em: 10/06/2018

\section{A Transmissão de Conhecimentos como Condição para a Criatividade: o Papel Diretivo do Professor e a Criança Feliz}

\author{
Ana Carolina Galvão Marsiglia \\ Maria Cláudia da Silva Saccomani
}

\section{Resumo}

Este artigo versa sobre o desenvolvimento histórico-social da criatividade. Pretende-se mostrar que a criatividade não é um potencial individual inato que se desenvolve por meio de interações espontâneas com o ambiente cultural e tampouco contrária à transmissão sistemática de conhecimento. Assim, começamos o artigo com a problemática sobre a dicotomia entre criatividade e liberdade. Em seguida, nos dedicamos brevemente sobre o desenvolvimento psicológico humano, mais especificamente, da função psíquica imaginação, evidenciando que a criatividade exige transmissão de conhecimentos. Por fim, tecemos algumas considerações sobre o papel da educação escolar no processo de humanização dos indivíduos e ao desenvolvimento da criatividade.

Palavras-chave: Criatividade. Educação escolar. Psicologia histórico cultural. Pedagogia histórico-crítica. 


\begin{abstract}
Keywords:

Creativity. School

Education.

Historical-Cultural

Psychology.

Historical-Critical

Pedagogy.

The knowledge transmission as a condition for creativity: teacher's directive role and happy child

This article deals with the historical and social development of creativity. It is intended to show that creativity is not an innate individual potential that is developed through spontaneous interactions with the cultural environment and contrary to the systematic transmission of knowledge. Therefore, we begin the article with the issue of the dichotomy between creativity and freedom. Then we dedicate ourselves to write briefly about the human psychological development, specifically the psychic imagination function, demonstrating that creativity requires transmission of knowledge. Finally, we present some considerations on the role of education in the process of humanization of individuals and the development of creativity.
\end{abstract}

\title{
Resumen
}

La transmisión de conocimientos como condición para la creatividad: el papel directivo del profesor y el niño feliz

Este artículo versa sobre el desarrollo histórico-social de la creatividad. Se pretende mostrar que la creatividad no es un potencial individual innato que se desarrolla a través de interacciones espontáneas con el ambiente cultural y tampoco es contraria a la transmisión sistemática de conocimiento. Por tanto, empezamos el artículo con la problemática sobre

Palabras clave:

Creatividad.

Educación escolar.

Psicología histórica cultural. Pedagogía histórica-crítica. la dicotomía entre creatividad y libertad. Enseguida, nos dedicamos brevemente sobre el desarrollo psicológico humano, más específicamente, de la función psíquica imaginación, que evidencia que la creatividad exige transmisión de conocimientos. Por último, hacemos algunas consideraciones sobre el papel de la educación escolar en el proceso de humanización de los individuos y al desarrollo de la creatividad.. 


\section{Introdução}

Por detrás de qualquer pessoa, há uma história de vida, uma infância. Essa ideia, embora pareça de extrema obviedade, é importante para fundamentar nossa oposição às concepções naturalizantes e espontaneístas do desenvolvimento humano e da criatividade, posto que analisamos o desenvolvimento do ato criativo em seu caráter histórico e social.

A ideia de que um sujeito criativo que se destaca perante os demais aparenta ter um dom, uma personalidade ou um talento inato, desconsidera as condições objetivas de vida e educação que lhe foram ofertadas e proporcionaram seu desenvolvimento. Dessa forma, o desconhecimento acerca do que é e o que promove o desenvolvimento do psiquismo humano, dá margem a concepções inatistas, naturalizantes e espontaneístas sobre o ato criativo.

Abordar as relações entre a transmissão de conhecimentos e a criatividade, tendo como foco a educação escolar, é tarefa complexa e nesse artigo, portanto, apenas problematizamos a necessidade de fomentar o debate acerca dessa temática com os profissionais que se dedicam ao trabalho educativo desde a infância. Tomamos como referência a pedagogia histórico-crítica e, assim, afirmamos que a educação escolar tem a função precípua de transmitir os conhecimentos científicos, artísticos e filosóficos em sua máxima expressão, desde os primeiros anos de vida.

Nosso objetivo é, pois, refletir sobre como os professores, por meio de suas ações concretas, poderão lidar com o fenômeno da criatividade avançando na direção da captação do fenômeno em sua essência e não mais a partir de suas manifestações aparentes. Em síntese, pretende-se mostrar que a criatividade se constitui numa capacidade exclusivamente humana e altamente complexa, que depende intrinsicamente do trabalho pedagógico orientado pelo que há de mais desenvolvido no mundo da cultura. É preciso superar dicotomias muito presentes nos discursos pedagógicos contemporâneos como, por exemplo, as oposições entre criação e reprodução, construção e transmissão do conhecimento, inovação e conservação, entre outras.

Nessa direção, o título desse artigo nos remete a uma ideia bastante comum nas concepções pedagógicas contemporâneas: a transmissão direta e intencional dos saberes escolares das diferentes áreas do conhecimento presentes nos currículo escolares inibiria a iniciativa e a criatividade do aluno, tornando-o passivo e sem qualquer autonomia. Em contrapartida, afirmamos que deixar que o processo educativo seja guiado de modo livre e espontâneo pelo aluno não significa garantir o direito da criança de brincar, divertir-se, e, portanto, ser feliz. Muito pelo contrário, entendemos que significa negar-lhe o direito de ampliar o seu conhecimento sobre a realidade e manter-lhe reprodutora das relações sociais alienadas que vivencia em seu cotidiano.

A própria utilização do verbo transmitir vem sendo erroneamente entendido com sentido pejorativo. Compreendemos, porém, que a educação escolar deve planejar e organizar o fazer pedagógico 
dirigido às crianças levando em consideração as condições físicas e psicológicas de cada faixa etária. Nesse sentido, tratar da transmissão de cultura, por exemplo, na educação infantil, não significa afirmar uma ação isolada em que o professor é o centro do processo e o aluno é passivo, mas ao mesmo tempo, não significa afirmar que a criança dirige o processo educativo. Transmitir cultura deve ser entendido em sentido amplo, isto é, há diferentes formas de se transmitir cultura, que dependerão dos indivíduos com os quais trabalharemos e seus diferentes momentos de desenvolvimento.

Todos aqueles que se dedicam à educação escolar já se depararam com a contraposição entre transmissão e criatividade/autonomia/liberdade. Muitas vezes, não tanto pela via direta da criatividade, mas de modo geral, como uma crítica que nos fazem quando defendemos a intervenção intencional do professor no processo educativo desde o primeiro ano de vida. Por isso, iniciaremos com a problemática sobre a dicotomia entre criatividade e liberdade, visando explicitar que a segunda pode, em lugar de oferecer verdadeiramente a emancipação do sujeito, colaborar para sua adaptação. Em seguida, para qualificar a ideia que sustentamos de que a criatividade exige transmissão de conhecimentos, nos dedicaremos brevemente sobre o desenvolvimento psicológico humano, especificamente, da função psíquica imaginação e seu caráter humanizador. Por fim, teceremos algumas considerações sobre o papel da educação escolar nesse processo de humanização dos indivíduos.

\section{Crianças criativas ou adaptadas ao meio?}

Para analisar a relação entre criatividade-adaptação-liberdade, iniciaremos abordando brevemente as pedagogias do "aprender a aprender", que acentuam o caráter adaptativo dos seres humanos e têm se firmado hegemonicamente na atualidade, sendo diferentes discursos (construtivismo, pedagogia das competências, pedagogia de projetos, teoria do professor reflexivo etc.) variantes de uma mesma concepção. Não se trata de um grupo inteiramente homogêneo, mas são concepções pedagógicas que partilham a ideia de que a transmissão direta e intencional de conhecimentos se opõe à aprendizagem, assim como, à criatividade.

Segundo Duarte (2004), o lema “aprender a aprender" não significa, como poderia parecer à primeira vista, a defesa de uma educação escolar que fomente a criatividade e a autonomia intelectual em oposição a uma educação pautada na reprodução mecânica de conteúdos e na heteronomia. O lema "aprender a aprender" conteria, segundo o citado autor, uma atitude fundamentalmente negativa em relação à educação escolar.

Não seria exagero afirmar que o lema "aprender a aprender" se firmou no âmbito educacional como um legítimo símbolo de criatividade. Assim sendo, existe a valorização de uma suposta criatividade na construção individual de conhecimentos. A finalidade é que o aluno pense de maneira criativa e livre. Portanto, endeusa-se a criatividade e, ao mesmo tempo, transforma-a em uma categoria esvaziada e 
empobrecida de conteúdos, sem relação com a transmissão direta e intencional dos conhecimentos historicamente acumulados ou, ainda, totalmente oposta a ela.

As pedagogias do "aprender a aprender", por negarem a função do trabalho educativo de transmissão de conhecimento, que para a pedagogia histórico-crítica, caracteriza a especificidade da educação escolar, acabam por defender uma visão equivocada do que seja uma escola democrática, porque esvaziada de seu papel de socialização do conhecimento, a escola deixa de garantir a possibilidade real de participação dos indivíduos na sociedade.

O pesquisador e biólogo Jean Piaget (1896-1980), considerado expoente da abordagem construtivista $^{1}$, se dedicou ao problema do conhecimento: o que é, como o ser humano chega a ele, como se passa de um conhecimento a outro etc. Sua teoria destinava-se a tentar explicar o conhecimento baseando-se na biologia, fazendo um elo entre essa ciência e a filosofia, com dados empíricos. Segundo Azenha (1993, p. 8), “[...] a formação típica de cientista leva-o a procurar um suporte experimental para suas especulações filosóficas, de forma a poder construir uma epistemologia de base biológica".

O modelo piagetiano de análise da inteligência está baseado nas relações que se estabelecem entre o organismo e meio ambiente, sendo que tal processo se dá pela adaptação do organismo ao meio e por sua organização interna. Assim, a adaptação é bem-sucedida se o organismo atinge equilíbrio entre assimilação dos elementos da realidade (exterior) e acomodação a essa realidade dos esquemas internos do organismo. Nas palavras de Piaget (1982, p. 18):

Em resumo, a adaptação intelectual, como qualquer outra, é um estabelecimento de equilíbrio progressivo entre um mecanismo assimilador e uma acomodação complementar. O espírito só pode encontrar-se adaptado a uma realidade se houver uma acomodação perfeita, isto é, se nada mais vier, nessa realidade, modificar os esquemas dos sujeitos. Mas, inversamente, não há adaptação se a nova realidade tiver imposto atitudes motoras ou mentais contrárias às que tinham sido adotadas no contato com outros dados anteriores: só há uma adaptação se houver coerência, logo assimilação. [...] Mas em todos os casos, sem exceção, a adaptação só se considera realizada quando atinge um sistema estável, isto é, quando existe um equilíbrio entre acomodação e assimilação.

A busca de equilíbrio entre assimilação e acomodação, que gera a adaptação dos indivíduos ao meio é central na teoria piagetiana. Assim, o indivíduo está predestinado a reconstruir (ou reinventar) o conhecimento segundo suas possibilidades. E nesse sentido, o professor toma lugar acessório a essa reconstrução.

Se a transmissão do conhecimento não produz no sujeito que aprende o processo de desenvolvimento de suas ferramentas culturais que possibilitam a aprendizagem, então a transmissão 
apresenta-se, na teoria piagetiana, totalmente dependente do processo interno de reinvenção dos instrumentos cognitivos. Ainda que Piaget reconheça a existência da "transmissão social", coloca-a em posição de subordinação aos processos psicológicos internos de reestruturação do real. Dessa forma, resta à educação escolar apenas a escolha entre servir a esses processos internos ou ser um obstáculo ao desenvolvimento dos mesmos.

Podemos perceber que para referendar as ideias piagetianas, é preciso considerar a transmissão do conhecimento como algo nocivo, porque impediria o aluno de refletir por si, inviabilizando seu crescimento intelectual. Destarte, quanto menos se ensina, mais se aprende, como assevera Becker (1993, p. 71, grifo do autor):

Quando um professor ensina um conteúdo aos seus alunos [...], ele atravessa todo o processo de construção do conhecimento obstruindo o processo de abstração reflexionante. Em nome da transmissão do conhecimento ele impede a construção das estruturas básicas de todo o conhecer, o a priori de toda a compreensão. É isto que Piaget quer dizer ao afirmar que toda vez que ensinamos algo à criança, impedimos que ela invente esta e tantas outras coisas.

Assim, no modelo construtivista, com o mínimo de interferência do professor e de qualquer tipo de transmissão, afirma o pesquisador suíço: “A 'escola ativa' baseia-se na ideia de que as matérias a serem ensinadas à criança não devem ser impostas de fora, mas redescobertas pela criança por meio de uma verdadeira investigação e de uma atividade espontânea” (PIAGET, 1998, p. 42), pois se “[...] o objetivo da educação é formar seres autônomos, então o ensino baseado na transmissão oral e na autoridade deve ser abolido.” (PARRAT-DAYAN e TRYPHON, 1998, p. 12, grifo nosso).

Concordamos que a educação escolar deva desenvolver a criatividade e a autonomia dos alunos. Entretanto, a concepção de criatividade presente nas pedagogias do “aprender a aprender" está intrinsecamente voltada à ideia de espontaneidade e adaptação. Pode-se dizer que, para as concepções pedagógicas hegemônicas, pensar de maneira criativa significa pensar por si mesmo, o que por sua vez, seria resultado do aprender sozinho sem a interferência prejudicial do professor.

Duarte (2004) afirma que um dos princípios valorativos que caracterizam o lema "aprender a aprender" é a formação de indivíduos com potencial adaptativo, sendo um dos objetivos da educação desenvolver nos sujeitos a capacidade de adaptação às mudanças aceleradas que caracterizam a sociedade atual. Os educandos, nesse contexto de transformações rápidas e inesperadas, precisariam ter a capacidade de buscar a construção de conhecimentos por si próprios, para que dessa forma, consigam se adaptar às exigências da sociedade contemporânea. Como nos mostra esse autor: 
O "aprender a aprender" aparece na sua forma mais crua, mostra assim seu verdadeiro núcleo fundamental: trata-se de um lema que sintetiza uma concepção educacional voltada para a formação da capacidade adaptativa dos indivíduos. Quando educadores e psicólogos apresentam o "aprender a aprender" como síntese de uma educação destinada a forma indivíduos criativos, é importante atentar para um detalhe fundamental: essa criatividade não deve ser confundida com busca de transformações radicais na realidade social, busca de superação radical da sociedade capitalista, mas sim criatividade em termos de capacidade de encontrar novas formas de ação que permitam melhor adaptação dos ditames do processo de produção e reprodução do capital (idem, p.42).

Nota-se, pois, que a concepção de criatividade presente no lema "aprender a aprender" traz em seu bojo a adaptação, ou melhor, a concepção de criatividade presente no lema "aprender a aprender" está intrinsecamente ajustada aos moldes da lógica do capital.

Considerando que no próximo item analisaremos o complexo desenvolvimento histórico-social de nosso psiquismo e ressaltaremos a criatividade como seu produto, precisamos agora destacar o significado de liberdade para a pedagogia histórico-crítica. Essa é uma discussão importante, visto que tipicamente (como já sublinhamos) as pedagogias do "aprender a aprender" consideram que a diretividade do processo educativo se configuraria como violência à criatividade e à liberdade das crianças.

Saviani (2008) explica que durante a Idade Média a essência humana estava articulada à criação divina, o que determinava seus destinos e possibilidades. Diferentemente, na época moderna, a burguesia em ascensão vai defender a ideia de igualdade entre os homens, como produto da história humana e não como determinação transcendental. Isso exigia uma reforma, "[...] substituindo uma sociedade com base num suposto direito natural por uma sociedade contratual” (idem, p. 32). Nesse novo modelo, era preciso defender uma escolarização para todos, de modo que os indivíduos pudessem ser convertidos de súditos em cidadãos. Dessa forma, os homens seriam livres e assim poderiam fazer suas escolhas. Ocorre, porém, que a "liberdade" da classe trabalhadora dependia de a classe dominante querer ou não comprar a força de trabalho disponível. Não é difícil concluir que o resultado é a exploração do trabalhador que, portanto, não é livre.

Na medida em que a burguesia se consolida como classe dominante, mudam seus interesses, que agora se voltarão à manutenção e não mais à transformação da sociedade. Em termos pedagógicos, isso significou passar da pedagogia da essência para a pedagogia da existência, defendendo as diferenças entre os seres humanos como algo a ser respeitado e aceito. Assim, “[...] a pedagogia da existência vai ter esse caráter reacionário, isto é, vai contrapor-se ao movimento de libertação da humanidade em seu conjunto, vai legitimar as desigualdades, legitimar a dominação, legitimar a sujeição, legitimar os privilégios" 
(idem, p. 34). Emerge então, a contraposição da Escola Nova à Escola Tradicional, que por sua vez, será a raiz daquilo que hoje se expressa nas pedagogias do "aprender a aprender".

A Escola Nova e as pedagogias do "aprender a aprender", portanto, vão comungar do princípio de que as diferenças entre os indivíduos devem ser respeitadas. No entanto, essas "diferenças", não expressam aquilo que de fato deve ser respeitado: a multiplicidade de culturas. $\mathrm{O}$ que esse discurso produz é, na verdade, uma desigualdade de acesso ao melhor do patrimônio humano genérico, travestido como respeito.

Nosso entendimento é de que essa disparidade, na escola, se traduz no ensino mínimo, empobrecido, fragmentado, que oferece à classe trabalhadora, presente na escola pública, as migalhas dos conhecimentos historicamente produzidos pelo conjunto dos seres humanos. Com esses farelos, não há condição adequada de se compreender a sociedade em suas múltiplas determinações e, portanto, não há condição de liberdade. Como explica Saviani (idem, p. 45) “[...] o dominado não se liberta se ele não vier a dominar aquilo que os dominantes dominam. Então, dominar o que os dominantes dominam é condição de libertação". Portanto, é necessário garantir que os filhos da classe trabalhadora dominem os bens culturais que a burguesia tem ao seu alcance, pois somente com a classe trabalhadora no exercício desse domínio, formar-se-á um psiquismo que preparará os indivíduos para a criação de modos de produção a seu favor.

Para compreender o processo educativo como algo libertador, é preciso partir de uma concepção de ser humano que o entende como ser social, cultural, talhado historicamente pelo trabalho (como veremos mais adiante em sua relação com a conceituação da própria imaginação). Com efeito, os seres humanos expressam sua estrutura na dialética entre situação, liberdade e consciência (SAVIANI, 2014).

No aspecto da situação, percebemos que os indivíduos estão inseridos em determinados contextos que influenciam a formação humana. Entretanto, dialeticamente, os sujeitos também transformam seus contextos, produzindo uma situação transformada (cultura). Isso nos leva a afirmar que o ser humano não é totalmente determinado e, portanto, é livre e autônomo. Dessa forma, o segundo aspecto (pessoal) da estrutura dos seres humanos está relacionado à capacidade do sujeito de se relacionar, assumir posições, responsabilidades e compreender o outro também como sujeito e não como objeto. Isso nos encaminha para o terceiro aspecto da estrutura humana, a consciência. Para se colocar no ponto de vista do outro, se comunicar com ele e assim ultrapassar seus próprios limites, é preciso considerar o aspecto intelectual, cujo desenvolvimento (tendo em vista que o ser humano é histórico) não é natural e se estabelece na dependência das condições de vida e educação proporcionadas.

[...] podemos considerar que, sendo a educação a formação do homem, entendida em seu conceito amplo, ela não é outra coisa senão o próprio processo de produção da realidade humana em seu conjunto. 
De outro lado, considerando-se que a natureza humana não é dada ao homem, mas é por ele produzida sobre a base da natureza biofísica, a educação, em termos estritos, isto é, a educação enquanto atividade intencional, consiste no ato de produzir em cada indivíduo a humanidade que é produzida historicamente pelo conjunto dos homens. Isso significa, como assinalei no livro Pedagogia histórico-crítica, que o objeto da educação diz respeito, de um lado, à identificação dos elementos culturais que precisam ser assimilados pelos indivíduos da espécie humana para que eles se tornem humanos e, de outro lado e concomitantemente, à descoberta das formas mais adequadas para atingir esse objetivo. De maneira simples, podemos, então, considerar a educação como a promoção do homem (SAVIANI, 2014, p. 54, grifo do autor).

Destarte, o que procuramos demonstrar até aqui é que a educação pode servir à adaptação ou à liberdade; pode instrumentalizar os indivíduos para a criatividade ou mantê-los na esterilidade; pode emancipar ou aprisionar os seres humanos em suas condições de vida. Os belos discursos sobre "formar o sujeito crítico, conscientizado, cidadão", não passam de palavras ao vento quando não se sustentam em reflexões teórico-práticas sobre o desenvolvimento humano e o papel da escola nesse processo. Esse é o mote de nossa discussão no próximo item.

\section{A imaginação e a criatividade}

Nesse item, traremos à baila a função psíquica imaginação e a importância da apropriação, pelos indivíduos, do que há de mais desenvolvido no mundo da cultura para que essa função se desenvolva de forma elevada. Ademais, destacaremos a necessidade de se entender a imaginação à luz de uma perspectiva histórico-cultural, contrapondo-nos às visões naturalizantes e espontaneistas sobre a capacidade humana de imaginar e criar. Mas, afinal, o que significa afirmar a gênese histórico-cultural da imaginação?

Afirmar que a imaginação apenas se desenvolve histórico e socialmente significa dizer que essa função não está assegurada biologicamente aos seres humanos no momento do nascimento, ou seja, é cultural e, mais do que isso, é uma função que se desenvolve como expressão máxima do desenvolvimento psíquico humano. Há que se ressaltar que, na sociedade capitalista, em face da alienação que lhe é inerente, a grande maioria da população não possui uma grande e rica imaginação (ao contrário do que muitos acreditam). Não se trata, porém, de um problema genético ou "falta de talento", mas sim da expressão psicológica da alienação. Ou seja: o indivíduo se aliena das condições que poderiam (e deveriam) ter promovido o desenvolvimento do pensamento altamente abstrato e, dessa forma, não desenvolve a imaginação e a criatividade, que depende de condições de vida e educação bem definidas. 
Em síntese, como explica Martins (2013), o desenvolvimento do psiquismo humano aponta para a superação, por incorporação, das funções psicológicas elementares, as funções de cunho fundamentalmente biológico e asseguradas pela natureza, em direção às funções psicológicas superiores, aquelas culturalmente formadas.

Baseando-nos no materialismo histórico-dialético, partimos da concepção de criatividade como uma capacidade humana que tem sua gênese na atividade de trabalho. A característica essencial do trabalho é a de que o produto da atividade existe primeiro na mente do sujeito. Segundo Marx (2011, p. 212), uma das características que diferem a atividade do ser humano da atividade dos animais é o caráter teleológico do trabalho que "[...] imprime ao material o projeto que tinha conscientemente em mira, o qual constitui a lei determinante do seu modo de operar e ao qual tem de subordinar sua vontade".

Diferente dos animais que apenas se adaptam à natureza, o ser humano transforma e domina a natureza de acordo com suas necessidades e, nesse movimento, também se transforma. A criação principia no momento em que o ser humano antecipa mentalmente o resultado a ser alcançado na realidade, ou seja, há na mente do sujeito uma imagem de algo que não existe ainda na realidade objetiva, mas poderá vir a existir, se a atividade for objetivada com sucesso. Observemos, pois, que se adaptação da natureza a si não é a premissa humana, mas sim o inverso, isso nos evidencia o caráter histórico do ser humano, conforme já destacamos anteriormente.

A imaginação é a imagem antecipada do produto da atividade, isto é, nos possibilita representar o resultado final da nossa atividade antes de executá-la. Destaca-se, porém, que é impossível entender o processo psíquico imaginação isoladamente, assim como não se pode compreender qualquer função psicológica dessa forma. Assim, ao tratar do desenvolvimento da imaginação, não se pode entendê-la como uma função única e especial, desvinculando-a do desenvolvimento das demais funções, pois fazer isso seria tratá-la como "dom" ou "talento".

Como explica Martins (2013), o psiquismo humano é um sistema interfuncional e compreende os processos funcionais sensação, percepção, atenção, memória, linguagem, pensamento, imaginação, emoções e sentimentos. Tais processos são os responsáveis pela formação da imagem subjetiva da realidade objetiva. Essa imagem apenas se forma e se transforma por meio da interfuncionalidade dos processos psíquicos.

Seria impossível explicar ao leitor cada um desses processos no espaço desse texto, mas, ao mesmo tempo, não é possível falar somente da imaginação, justamente por conta da interfuncionalidade a que nos referimos. Todas as funções se desenvolvem por meio de imagens e, nesse sentido, todas são imaginativas (MARTINS, 2013). Faz-se necessário, pois, enfatizar a relação entre a imaginação e outras funções psicológicas. 
A característica mais essencial da imaginação é a modificação das conexões já estabelecidas entre sujeito e objeto de modo a produzir uma imagem nova. Assim, as conexões habituais são rompidas e reordenadas do ponto de vista abstrato. Como afirma Rubinstein (1967, p. 361), a imaginação “[...] está inseparavelmente vinculada com nossa aptidão de modificar o mundo, de transformar ativamente a realidade e de criar algo novo". E, tal como assevera Martins (2011, p. 50), o processo funcional imaginação é analítico-sintético, pois “[...] na transformação de representações já construídas, condição para a imaginação, a análise opera desagregando elementos da imagem existente visando a uma nova combinação, que por sua vez, determina nova síntese". Assim sendo, o conteúdo da imaginação, a princípio, é a memória. De acordo com Rubinstein (1967, p. 361-362, grifo do autor):

A imaginação significa uma separação da existência passada, uma reforma do que está dado e, sobre esta base, a produção de novas imagens, que ao mesmo tempo são produtos da atividade criadora do homem e exemplo dela. A diferença fundamental da imaginação propriamente dita com respeito à memória imaginativa se deve a outro enfoque da realidade. As imagens mnêmicas representam uma reprodução da experiência. A função da memória consiste em conservar o mais fielmente possível os resultados da experiência; a imaginação, em transformá-la.

A imaginação, como formação de novas conexões entre imagem e objeto (MARTINS, 2013), tem como ponto de partida, a imagem já registrada na memória, ou seja, as conexões estabelecidas entre dada imagem e dado objeto. A imaginação visa a transformação. Transformar, como explica Martins (idem, p. 271- 272): “[...] do latim transformare, significa conferir outra forma por superação dos limites da forma anterior ou conquistar outro estado ou condição”. Assim sendo,

[...] a imaginação tenciona reprodução e transformação, e dessa forma, aparece como expressão máxima da consciência do psiquismo humano. Assim, enquanto a memória se orienta para o passado, a imaginação em aliança com o pensamento abstrato, se orienta pelo futuro. A imaginação expressa-se efetivamente quando a transformação da imagem deixa de ser involuntária e passa a orientar conscientemente a atividade (SACCOMANI, 2016, p.71).

Para, de fato, transformar as conexões habituais e projetar algo novo, faz-se necessário o pensamento abstrato, altamente desenvolvido. Com efeito, há três processos funcionais inseparáveis: imaginação, memória e pensamento. Como também afirma Saccomani (idem, p. 72): 
As funções não existem por si próprias e independentes umas das outras. Nesse sentido, quando se afirma que determinado indivíduo não é criativo, ou então que não possui uma rica imaginação, não se trata de um déficit específico da função psicológica imaginação. Em realidade, o problema da pouca criatividade não deve ser tratado como uma característica pessoal e exclusiva, mas sim como manifestação direta de um déficit no próprio desenvolvimento do psiquismo dos sujeitos, ou melhor, um déficit no ensino. O foco não deve ser colocado no indivíduo, mas sim na sociedade e na qualidade dos processos de ensino e aprendizagem.

Portanto, à luz das abstrações do pensamento, o indivíduo pode romper com aquilo que memorizou, mudando a imagem do que existe, daquilo que já foi e do que é, em nome de algo que possa vir a ser. Mas tudo isso está na dependência do projeto histórico que se tem para uma sociedade. E a sociedade capitalista, bem como sua educação escolar, não tem oferecido as condições objetivas para um projeto não-alienado.

Martins (2013, p. 239), baseando-se em Vigotski, assevera que “[...] os verdadeiros produtos da imaginação começam a se expressar na idade de transição, quando os pseudoconceitos formulados pelo adolescente vão cedendo lugar aos conceitos, nos quais radica o pensamento abstrato". Afastado das condições objetivas e subjetivas que permitem ao sujeito o desenvolvimento do pensamento abstrato, não se ultrapassa as relações sensoriais imediatas com os objetos. Com efeito, faz-se necessário superar o pensamento empírico em direção ao pensamento por conceitos, que por sua vez, exige uma relação abstrata e mediada com a realidade, produzindo-se momentos de suspensão da experiência imediata do indivíduo ${ }^{2}$.

Vygotski (2009) afirmava a existência de um vínculo entre a apropriação da cultura e o desenvolvimento da imaginação. É nessa direção que o psicólogo soviético considerou que a imaginação da criança é mais pobre do que a imaginação do adulto, ao contrário do que as concepções hegemônicas e o senso comum afirmam. Segundo Martins (2013, p. 238) se o desenvolvimento da função psíquica imaginação fosse mais rico na infância do que na idade adulta, este seria um percurso contrário à concepção de desenvolvimento, pois a imaginação seria uma função psíquica que se atrofiaria, isto é, seria um processo "involutivo" e não se ampliaria no decorrer do desenvolvimento cultural do indivíduo. De acordo com Rubinstein (1967, p. 373), o desenvolvimento da imaginação na criança:

[...] é mais débil que no adulto. O "voo da realidade" na fantasia infantil consiste principalmente em que a criança não pode ter em conta as leis da realidade objetiva, que desconhece, de modo que violenta facilmente a realidade da vida. A aparente abundância das fantasias infantis é, na realidade, em 
sua maior parte, a maior expressão da debilidade de seu pensamento crítico do que a força de sua imaginação.

O limite da imaginação infantil é expressão do limite do desenvolvimento de seu pensamento, que ainda pretere as leis internas essenciais e não visíveis que regem a existência objetiva dos fenômenos. Aquilo que muitas pessoas consideram ser uma "rica imaginação", em realidade, é a expressão do sincretismo e do pensamento por complexos ${ }^{3}$.

Apenas por meio do pensamento conceitual, no qual radica o pensamento abstrato, os verdadeiros produtos da imaginação podem aparecer (MARTINS, 2013). Nesse sentido, a educação escolar deve visar o máximo desenvolvimento do pensamento do indivíduo, isto é, o pensamento conceitual maximamente abstrato. Assim, a aprendizagem dos conteúdos escolares é condição para o desenvolvimento do pensamento e, nesse sentido, faz-se necessária a apropriação dos conhecimentos não-cotidianos, a apropriação dos sistemas de signos e dos conceitos mais complexos produzidos pelo trabalho intelectual da humanidade.

A educação escolar desenvolve a criatividade quando cumpre sua função por excelência de socializar os conhecimentos científicos, artísticos e filosóficos em suas máximas expressões, como é preconizado pela pedagogia histórico-crítica. É desse modo que a educação escolar faz surgir o "novo" em cada indivíduo singular. Assim, o trabalho do professor é extremamente criativo, pois, à medida que se objetiva no educando, cria algo novo na individualidade desse aluno.

Defender que o professor transmita de modo direto e intencional, ou melhor, defender o papel diretivo do professor como profissional que tem autonomia intelectual para pensar sua prática pedagógica não é uma contradição à afirmação que a criança deve ser ativa no processo de aprendizagem. Dirigir o processo de ensino e aprendizagem não é sinônimo de tornar a criança passiva. Muito pelo contrário, significa permitir a ampliação de sua visão se mundo, da realidade da qual ainda desconhece, mas que o professor deve conhecer em sua essência, de modo a apresentá-la ao aluno.

A apropriação daquilo que já existe no mundo da cultura é condição para a criação de algo novo. Como mostra-nos o psicólogo soviético:

Qualquer inventor, mesmo um gênio, é sempre um fruto de seu tempo e de seu meio. Sua criação surge de necessidades que foram criadas antes dele e, igualmente apoia-se em possibilidades que existem além dele. Eis porque percebemos uma coerência rigorosa no desenvolvimento histórico da técnica e da ciência. Nenhuma invenção ou descoberta científica pode emergir antes que aconteçam as condições materiais e psicológicas necessárias para seu surgimento. A criação é um processo de herança histórica em que cada forma que sucede é determinada pelas anteriores (VYGOTSKI, 2009, p. 42). 
Da mesma forma que o desenvolvimento individual implica saltos qualitativos, para que um gênio individual possa nos brindar em termos de humanidade com uma objetivação inovadora, muitos outros gênios ocultos ou ocultados na história também existiram.

A educação escolar não deve voltar-se àquilo que os alunos já possuem em seu cotidiano, pois dessa forma está tão somente repetindo a realidade alienada e nada de novo é formado no aluno. A função da escola é, pois, formar o novo em cada ser humano, levando-o a caminhos ainda não trilhados. Como afirma Saviani (2011, p. 201) "[...] o papel da escola não é mostrar a face visível da lua, isto é, reiterar o cotidiano, mas mostrar a face oculta, ou seja, revelar os aspectos essenciais das relações sociais que se ocultam sob os fenômenos que se mostram à nossa percepção imediata".

Novas objetivações artísticas, científicas, políticas e filosóficas já foram conquistadas pela humanidade. Entretanto, do ponto de vista dos sujeitos particulares, nem todos se apropriaram delas. Desse modo, não se pode dicotomizar criação e reprodução, pois como já afirmamos, algo pode ser um ato de reprodução, do ponto de vista humano genérico, e criativo do ponto de vista individual. Uma criança ao se apropriar da linguagem escrita, por exemplo, toma para si algo novo, até então desconhecido para ela, mas antigo do ponto de vista da humanidade. Não significa necessariamente algo novo para a sociedade, mas é novo no que se refere às funções psicológicas do indivíduo em formação.

Apenas para ilustrar nossa defesa de que a criatividade não pode ser compreendida como genialidade com a qual algumas pessoas foram agraciadas, faremos, nas considerações finais, referência a um dos maiores autores de todos os tempos, William Shakespeare ${ }^{4}$ (1564-1616).

\section{Considerações finais}

Primeiramente, destacamos nosso acordo com a afirmação de $\operatorname{Heliodora}^{5}$ (2014, p. 11), de que o dramaturgo inglês "[...] foi essencialmente um autor popular". A característica de sua linguagem em verso, por vezes considerada pomposa e erudita de tal modo que afastaria muita gente de sua obra, é explicada pela autora por um lado, porque Shakespeare era um homem de seu tempo (todos os autores desde a Grécia Antiga se utilizavam da escrita em verso). E por outro, porque essa forma de construção do texto favorece o ato teatral, pois quando os versos "[...] são ditos com entonação e ritmo devidos já sugerem o caminho para expressar o conteúdo de uma boa história” (idem, ibidem).

Também é importante salientar que a crítica à erudição, tratada como algo essencialmente negativo, demonstra uma postura contrária à defesa da pedagogia histórico-crítica, pois nosso entendimento é de que o ensino dos clássicos universais (e não apenas europeus, mas sem descartá-los) é fundamental para o desenvolvimento das máximas possibilidades dos indivíduos. 
Isso nos leva de volta a William Shakespeare. Um dos aspectos que torna esse autor um clássico é o fato de que seus temas são universais, porque tratam do humano: as relações interpessoais, a política, questões éticas e morais, a história etc.

Não houve sinal razoável que sugerisse, ainda que levemente, que o filho de John e Mary Shakespeare viesse a ser o maior autor dramático de todos os tempos. Gosto de acreditar que ele foi alçado a essa condição de forma muito justa, especialmente por causa do grande caso de amor com a humanidade vivido ao longo de toda a vida. Em todas as suas peças Shakespeare explora o potencial humano que o fascina e pelo qual cultiva curiosidade inesgotável. Nas ações dos homens Shakespeare encontrava sua essência, e por isso mesmo seu talento encontrou a melhor expressão na forma dramática. A riqueza do que Shakespeare tem a dizer sobre a humanidade que tanto amava aparece em centenas ou milhares das falas que escreveu. Dando um passeio por suas peças, podemos encontrar exemplos do muito que a leitura de cada uma delas pode nos trazer em termos de prazer e de enriquecimento (idem, $\mathrm{p}$. 29-30).

A genialidade de Shakespeare, como temos defendido, não "brotou" de suas entranhas. Suas condições de vida e educação foram fundamentais. Neto de um agricultor que trabalhava para uma família importante e filho de um comerciante que conseguiu comprar duas casas na cidade e chegou a ser prefeito de Stratford, William foi o terceiro rebento do casal John e Mary e o primeiro filho homem a chegar à vida adulta.

Sua formação escolar parece ter sido sólida ${ }^{6}$ e "Esse nível de conhecimento somado à sua aguçada inteligência, sem dúvida, deixou William preparado para assimilar tudo o que a vida à sua volta lhe oferecia" (idem, p. 14-15). A autora também sinaliza que uma atividade escolar pode ter ajudado Shakespeare a se desenvolver: um caderno no qual o aluno deveria anotar "[...] pensamentos e bons sentimentos, expressados de forma elegante e agradável, uma ótima preparação para um futuro escritor" (idem, p. 14). Além disso, educou-se com aulas de latim, retórica, lógica e estudo de comédias e tragédias gregas, também positivos para estimular o autor.

O jovem Shakespeare chega a Londres entre 1588 e 1590. Na capital, centro de disputas de poder, lugar de incentivo à cultura e às artes, William encontra, além da explosão do teatro como manifestação cultural valorizada ${ }^{7}$, ambiente rico em ideias e acontecimentos, fatores que vão influenciar o iniciante autor.

Elizabeth assumiu o trono em 1558, com a Inglaterra falida. Somente em 1588, com a vitória sobre a armada espanhola consegue um respiro administrativo, que dá origem ao teatro elisabetano, com um grupo de jovens poetas de classe média, que “[...] provavelmente tiveram oportunidade de ver o que 
restava do popular teatro medieval, associando muito contato com o teatro romano em seus estudos" (idem, p. 34). Esse grupo, inspirado pelo sucesso da poesia de sir Philip Sidney (um dos mais importantes poetas ingleses), utilizou-a como instrumento para aproveitar o melhor das diferentes correntes de dramaturgia.

Esse grupo, conhecido em seu conjunto como university wits [...] de algum modo percebeu que era preciso propor algo novo. Especialmente porque as peças apresentadas nos teatros profissionais não estavam mais atraindo nem satisfazendo um público agitado com mudanças, com descobertas geográficas e científicas, com acontecimentos políticos marcantes, entre eles a execução de Mary Stuart e a vitória inglesa sobre os espanhóis (idem, p. 34-35).

Aqui temos mais um indicativo de que o inglês não se tornou um grande autor "de dentro para fora", sem apropriar-se daquilo já produzido na história. Ademais, de acordo com Barbara Heliodora, Shakespeare chegou a Londres num panorama rico e variado de dramaturgia e seguiu o exemplo de seus antecessores, dominando diferentes linguagens, temas e recursos do teatro elisabetano.

Olhando para as peças que Shakespeare escreveu em seus primeiros anos, encontramos uma variedade de gêneros que pode muito bem sugerir que ele tenha inicialmente observado o que estava sendo apresentado e concluído que seu sucesso dependia da habilidade para dominar aquelas formas dramáticas (idem, p. 36).

O período denominado por Barbara Heliodora de "O aprendizado" reúne trabalhos de Shakespeare de 1590 a 1598. A autora não estabelece uma ordem cronológica entre esse período e às outras subdivisões que faz (obras de 1595 a 1597 aparecem naquilo que ela denomina "Liberdade do domínio da forma", por exemplo). O que Heliodora pretende é salientar justamente que os trabalhos de Shakespeare do período "O aprendizado" representam sua chegada a Londres e sua fase de experimentação com o vocabulário teatral com o qual toma contato. É nesse período que nos concentraremos visando evidenciar ao leitor, aspectos dessas obras que corroboram nossas afirmações sobre o papel da apropriação dos conhecimentos já objetivados, que possibilitam o ato criativo e novas objetivações.

Em “A comédia dos erros", William utiliza-se de Plauto, autor romano de comédias estudado por ele no período escolar. "Titus Andronicus" foi escrita logo depois de Shakespeare chegar a Londres, o que justificaria seu desconhecimento de problemas políticos e sociais mais amplos. Ainda que como obra de um aprendiz, Heliodora (idem, p. 61) destaca sua superioridade em relação a outras da época e assinala: 
De qualquer maneira, não é difícil encontrar no texto sementes das grandes obras da maturidade de Shakespeare, pois Titus, como Lear, comete um erro ao fazer uma escolha precipitada, o que detona toda a ação da peça. Tamora não deixa de ser um rascunho da futura Lady Macbeth, como Aaron, o mouro, é o rascunho para Iago de Otelo.

Na refinada peça "Trabalhos de amor perdido", Shakespeare explora talentosamente formas de falar de iletrados e nobres. Mas, segundo Heliodora (idem, p. 56), “[...] há também momentos que revelam a sua inexperiência [por exemplo], quando não chega a funcionar um espetáculo apresentado pelos aldeões [...]". Entretanto, serviu-lhe “[...] de aprendizado para o perfeito sucesso que terão futuramente os artesãos da peça 'Sonho de uma noite de verão"”.

“Os dois cavalheiros de Verona” é a primeira comédia romântica do dramaturgo e apresenta vários detalhes que demonstram ser William, ainda um aprendiz. Apesar disso, é uma obra importante porque permite observar Shakespeare utilizando recursos que se tornarão usuais dali em diante em seus trabalhos: inaugura o uso de uma personagem feminina travestida de rapaz e é também a primeira vez que usa uma escada para alcançar um andar mais alto, onde se encontra a amada do protagonista. Nessa peça a ideia não funciona bem, mas será fundamental em "Romeu e Julieta". Vale salientar ainda, em conformidade com o que vimos apresentando sobre a importância da apropriação dos significados constituídos histórico-socialmente e a relevância dos temas tratados pelo autor, que Heliodora (idem, p. 69) destaca que

Muito especialmente, neste caso [dessa peça], Shakespeare fala de gente cujos sentimentos, emoções e pensamentos serviam para mostrar que os personagens eram todos humanos, bons, maus, tristes, divertidos, piedosos ou pecadores quanto o público que ia ao teatro ver as peças.

Com "Henrique VI", William inventa, logo no inicio da carreira, um novo gênero teatral, a peça histórica (ampliando as possibilidades expressivas da peça crônica), em que um personagem histórico (monarca) é escolhido para servir de "[...] fio condutor para apresentar um tema a partir do qual o autor sente a necessidade de expressar-se" (idem, p. 76). Temos ainda compondo esse período, "Ricardo III", também do gênero de peça histórica, que tem o mérito de nos trazer aquele que é considerado o primeiro grande protagonista da obra shakespeariana.

O período denominado por Barbara Heliodora de "A maturidade" é aquele em que Shakespeare se arrisca pela primeira vez no gênero da tragédia, mas também é nele que escreve suas mais notáveis comédias (românticas e sombrias). Por isso, Heliodora (idem, p. 211) argumenta que é preciso “[...] 
aceitar o fato de Shakespeare ter alcançado, a partir dos primeiros anos do século XVII, em seu amadurecimento pessoal e artístico, um nível no qual o artista produz o melhor de sua obra”.

O que podemos concluir dessa breve exposição sobre Shakespeare e que se relaciona à discussão em tela nesse artigo, é que, quando a criatividade é analisada à luz de uma visão naturalizante e espontânea, contrária à transmissão de conhecimentos, isso encerra o empobrecimento da individualidade, contribuindo para uma perspectiva adaptativa, que não visa a transformação do indivíduo e da sociedade.

A imaginação, nesse sentido, vincula-se diretamente com a possibilidade de superação da sociedade capitalista, isto é, essa função possibilita a transformação da realidade objetiva e também individual. Imaginar algo novo, para além daquilo que já existe, exige um psiquismo altamente desenvolvido. Sabemos, porém, que os filhos da classe trabalhadora não têm acesso aquilo que há de mais rico no mundo da cultura.

À medida que compreendermos a criatividade como um comportamento complexo culturalmente formado, que funciona em aliança com outros comportamentos complexos, a educação escolar aparecerá como lócus privilegiado para que esse desenvolvimento, de fato, aconteça. Assim, a escola colocará os alunos em contato com as objetivações mais ricas já acumuladas pela humanidade (como Shakespeare, por exemplo), proporcionando o desenvolvimento pleno de todos os seres humanos.

\section{Notas}

1 Estamos tomando o construtivismo como referência por entender que é o carro-chefe das pedagogias do "aprender a aprender" na contemporaneidade. Ainda que muitos discursos pós-modernos tentem se afastar das ideias piagetianas, suas bases estão fortemente enraizadas nas premissas epistemológicas do pesquisador suíço.

2 Não temos condições nesse texto de nos estender na discussão sobre a formação de conceitos. Sugerimos a leitura de Martins (2013).

$3 \mathrm{O}$ pensamento sincrético e o pensamento por complexos são as duas primeiras fases do desenvolvimento do pensamento que vão desde a primeira infância até a adolescência - e somente após elas, desponta o pensamento conceitual. Segundo Vigotski (apud MARTINS, 2013), o desenvolvimento do pensamento passa por três etapas principais: o pensamento sincrético, o pensamento por complexos e o pensamento conceitual. Sendo assim, o desenvolvimento do pensamento por conceitos perpassa esses estágios, assumindo neles diferentes qualidades. Ultrapassa os limites desse artigo abordar as fases do desenvolvimento do pensamento e suas características essenciais.

4 Tendo em vista que recorrentemente a pedagogia histórico-crítica é acusada de ser conteudista e partilhar de uma visão eurocêntrica de mundo, na qual se valorizaria uma cultura distante da realidade, cotidiano e subjetividades nacionais e de grupos minoritários e excluídos, lembramos que esse é um entendimento equivocado e superficial dessa teoria pedagógica e de sua base filosófica materialista histórico-dialética. É preciso compreender os fenômenos na intervinculação entre singularidade-particularidade-universalidade, como tentamos sinalizar nesse texto.

5 Não é nosso objetivo centralizar as discussões desse texto na obra shakespeariana. Mas para dar solidez ao que apresentamos, estamos utilizando uma das obras de Barbara Heliodora, formada em Língua e Literatura Inglesas, doutora em Artes e considerada a maior especialista brasileira em Shakespeare.

6 Afirma Heliodora (2014, p. 17) que a escola frequentada por Shakespeare (gramar school) em Stratford era uma das que pagava melhores salários na Inglaterra e por sua localização contava com mestres graduados em Oxford.

$7 \mathrm{O}$ reconhecimento que dava ao teatro efervescência no século XVI, passou por um longo processo de amadurecimento, visto que foi introduzido na Inglaterra no século XII. 


\section{Referências}

AZENHA, M. G. Construtivismo: de Piaget a Emília Ferreiro. São Paulo: Ática, 1993.

BECKER, F. Educação e construção do conhecimento. Porto Alegre: Artmed, 2001.

DUARTE, N. Vigotski e o "aprender a aprender": crítica às apropriações neoliberais e pós-modernas da teoria vigotskiana. 3. ed. Campinas - SP: Autores Associados, 2004.

HELIODORA, B. Shakespeare: o que as peças contam: tudo o que você precisa saber para descobrir e amar a obra do maior dramaturgo de todos os tempos. Rio de Janeiro: Edições de Janeiro, 2014.

MARTINS, L. M. O desenvolvimento do psiquismo e a educação escolar: contribuições à luz da psicologia histórico cultural e da pedagogia histórico-crítica. Campinas: Autores Associados, 2013.

MARTINS, L. M. Pedagogia histórico-crítica e psicologia histórico-cultural. In: MARSIGLIA, A. C. G. (Org.). Pedagogia histórico-crítica: 30 anos. Campinas-SP: Autores Associados, 2011. p. 43-57.

MARX. K. O Capital: crítica da economia política. 29.ed. Rio de Janeiro: Civilização Brasileira, 2011. T.1, v.1.

PARRAT-DAYAN, S. e TRYPHON, A. Introdução. In: PIAGET, J. Sobre a pedagogia: textos inéditos. Organização e introdução de PARRAT-DAYAN, S. e TRYPHON, A. São Paulo: Casa do Psicólogo. 1998. p. 7-23.

PIAGET, J. Os procedimentos da educação moral. In: PIAGET, J. Sobre a pedagogia: textos inéditos. Organização e introdução de PARRAT-DAYAN, S. e TRYPHON, A. São Paulo: Casa do Psicólogo, 1998b. p. 2558.

O Nascimento da Inteligência na Criança. 4 ed. Rio de Janeiro: Zahar, 1982.

RUBINSTEIN, S. L. Principios de psicologia general. México: Grijalbo, 1967.

SACCOMANI, M. C. S. A criatividade na arte e na educação escolar: uma contribuição à pedagogia históricocrítica à luz de Georg Lukács e Lev Vigotski. Campinas-SP: Autores Associados, 2016.

SAVIANI, D. Escola e Democracia. Campinas-SP: Autores Associados, edição comemorativa, 2008.

Antecedentes, origem e desenvolvimento da pedagogia histórico- crítica. In: MARSIGLIA, Ana Carolina

Galvão (org.). Pedagogia histórico-crítica: 30 anos. Campinas: Autores Associados, 2011.p. 197-225.

O lunar de Sepé: paixão, dilemas e perspectivas na educação. Campinas-SP: Autores Associados, 2014.

VYGOTSKI, L. S. Imaginação e criação na infância - Tradução Zoia Prestes - São Paulo: Ática, 2009. 


\section{Revisores}
Língua Portuguesa Anna Paola Galvão Marsiglia
E-mail: paolamarsiglia40@gmail.com

\section{Língua Inglesa \\ Sandlei Moraes \\ E-mail: sandleimoraes@yahoo.com.br}

\begin{tabular}{l|l} 
Língua Espanhola & Patricio Miguel Trujillo Ortega \\
& E-mail: pamipmto@hotmail.com
\end{tabular}

